Review

\title{
NASA has Found the Most Distant Black Hole
}

\author{
${ }^{1}$ Relly Victoria Petrescu, ${ }^{2}$ Raffaella Aversa, ${ }^{2}$ Antonio Apicella and ${ }^{1}$ Florian Ion Tiberiu Petrescu

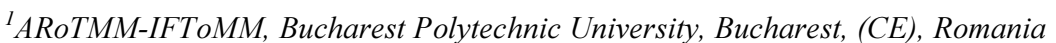 \\ ${ }^{2}$ Department of Architecture and Industrial Design, Advanced Material Lab, \\ Second University of Naples, 81031 Aversa (CE), Italy
}

Article history

Received: 09-01-2018

Revised: $12-01-2018$

Accepted: 18-01-2018

Corresponding Author: Florian Ion Tiberiu Petrescu ARoTMM-IFToMM, Bucharest Polytechnic University, Bucharest, (CE), Romania E-mail: scipub02@gmail.com
Abstract: Scientists have uncovered a rare relic from the early universe: the farthest known supermassive black hole. This matter-eating beast is 800 million times the mass of our Sun, which is astonishingly large for its young age. Researchers report the find in the journal Nature. "This black hole grew far larger than we expected in only 690 million years after the Big Bang, which challenges our theories about how black holes form," said study coauthor Daniel Stern of NASA's Jet Propulsion Laboratory in Pasadena, California. Astronomers combined data from NASA's Wide-field Infrared Survey Explorer (WISE) with ground-based surveys to identify potential distant objects to study, then followed up with Carnegie Observatories' Magellan telescopes in Chile. Carnegie astronomer Eduardo Bañados led the effort to identify candidates out of the hundreds of millions of objects WISE found that would be worthy of follow-up with Magellan. For black holes to become so large in the early universe, astronomers speculate there must have been special conditions to allow rapid growth -- but the underlying reason remains mysterious. The newly found black hole is voraciously devouring material at the center of a galaxy -- a phenomenon called a quasar. This quasar is especially interesting because it comes from a time when the universe was just beginning to emerge from its dark ages. The discovery will provide fundamental information about the universe when it was only $5 \%$ of its current age. "Quasars are among the brightest and most distant known celestial objects and are crucial to understanding the early universe," said co-author Bram Venemans of the Max Planck Institute for Astronomy in Germany. The universe began in a hot soup of particles that rapidly spread apart in a period called inflation. About 400,000 years after the Big Bang, these particles cooled and coalesced into neutral hydrogen gas. But the universe stayed dark, without any luminous sources, until gravity condensed matter into the first stars and galaxies. The energy released by these ancient galaxies caused the neutral hydrogen to get excited and ionize, or lose an electron. The gas has remained in that state since that time. Once the universe became reionized, photons could travel freely throughout space. This is the point at which the universe became transparent to light. Much of the hydrogen surrounding the newly discovered quasar is neutral. That means the quasar is not only the most distant -- it is also the only example we have that can be seen before the universe became reionized. "It was the universe's last major transition and one of the current frontiers of astrophysics," Bañados said. The quasar's distance is determined by what's called its redshift, a measurement of how much the wavelength of its light is stretched by the expansion of the universe before reaching Earth. The higher the redshift, the greater the distance and the farther back astronomers are looking in time when they observe the object. This newly discovered quasar has a redshift of 7.54, based on the detection of ionized carbon emissions from the galaxy that hosts the massive black hole. That means it took more than 13 billion years for the light from the quasar to reach us.

Keywords: NASA, Robotic Missions, Black Hole, Jet Propulsion Laboratory 


\section{Introduction}

Scientists have uncovered a rare relic from the early universe: the farthest known supermassive black hole. This matter-eating beast is 800 million times the mass of our Sun, which is astonishingly large for its young age. Researchers report the find in the journal Nature.

"This black hole grew far larger than we expected in only 690 million years after the Big Bang, which challenges our theories about how black holes form," said study co-author Daniel Stern of NASA's Jet Propulsion Laboratory in Pasadena, California.

Astronomers combined data from NASA's Wide-field Infrared Survey Explorer (WISE) with ground-based surveys to identify potential distant objects to study, then followed up with Carnegie Observatories' Magellan telescopes in Chile. Carnegie astronomer Eduardo Bañados led the effort to identify candidates out of the hundreds of millions of objects WISE found that would be worthy of follow-up with Magellan.

For black holes to become so large in the early universe, astronomers speculate there must have been special conditions to allow rapid growth -- but the underlying reason remains mysterious.

The newly found black hole is voraciously devouring material at the center of a galaxy -- a phenomenon called a quasar. This quasar is especially interesting because it comes from a time when the universe was just beginning to emerge from its dark ages. The discovery will provide fundamental information about the universe when it was only $5 \%$ of its current age.

"Quasars are among the brightest and most distant known celestial objects and are crucial to understanding the early universe," said co-author Bram Venemans of the Max Planck Institute for Astronomy in Germany.

The universe began in a hot soup of particles that rapidly spread apart in a period called inflation. About 400,000 years after the Big Bang, these particles cooled and coalesced into neutral hydrogen gas. But the universe stayed dark, without any luminous sources, until gravity condensed matter into the first stars and galaxies. The energy released by these ancient galaxies caused the neutral hydrogen to get excited and ionize, or lose an electron. The gas has remained in that state since that time. Once the universe became reionized, photons could travel freely throughout space. This is the point at which the universe became transparent to light.

Much of the hydrogen surrounding the newly discovered quasar is neutral. That means the quasar is not only the most distant -- it is also the only example we have that can be seen before the universe became reionized.

"It was the universe's last major transition and one of the current frontiers of astrophysics," Bañados said.

The quasar's distance is determined by what's called its redshift, a measurement of how much the wavelength of its light is stretched by the expansion of the universe before reaching Earth. The higher the redshift, the greater the distance and the farther back astronomers are looking in time when they observe the object. This newly discovered quasar has a redshift of 7.54, based on the detection of ionized carbon emissions from the galaxy that hosts the massive black hole. That means it took more than 13 billion years for the light from the quasar to reach us.

Scientists predict the sky contains between 20 and 100 quasars as bright and as distant as this quasar. Astronomers look forward to the European Space Agency's Euclid mission, which has significant NASA participation and NASA's Wide-field Infrared Survey Telescope (WFIRST) mission, to find more such distant objects.

"With several next-generation, even-more-sensitive facilities currently being built, we can expect many exciting discoveries in the very early universe in the coming years," Stern said (Landau and Bañados, 2017).

Caltech in Pasadena, California, manages JPL for NASA (Aversa et al., 2017a-e; 2016a-o; Berto et al., 2016a-d; Mirsayar et al., 2017; Petrescu and Petrescu, 2016a-c; 2013a-d; 2012a-d; 2011a-b; Petrescu, 2016; 2012a-b; 2009; Petrescu and Calautit, 2016a-b; Petrescu et al., 2016a-c; Petrescu et al., 2017 a-1).

\section{Materials and Methods}

A black hole is an astronomical object limited by an area within which the gravitational field is so strong that nothing can escape from within that surface, also known as the "event horizon". Even electromagnetic radiation (eg light) can't escape from a black hole, so the inside of a black hole is not visible, hence the name. The black hole has at its center a region known as "singularity".

On the boundary surface gravity is so large that no beam of light within the hole has enough energy to escape. At this limit the gravitational shift towards red is infinitely high.

The gravitational escape velocity is at the limit surface equal to the speed of light so that the radius of the boundary surface is equal to the radius of the circular trajectory, called the "Schwarzschild radius".

The concept of objects whose gravitational field is too strong to allow light to escape was first proposed in the eighteenth century by John Michell and Pierre-Simon Laplace. The first modern solution to the general theory of relativity regarding black holes was found by Karl Schwarzschild in 1916, although its interpretation as a region of space from which nothing can escape was not fully appreciated for another four decades. Long considered as a mathematical curiosity, only in the 1960s a number of theoretical works showed that black holes were a generic consequence of general relativity. The discovery of neutron stars has prompted interest in compact objects, formed by gravitational collapse as a possible astrophysical reality. 
Black star holes are formed by the collapse of large mass stars in a supernova at the end of their lives. After formation, the black hole can continue to grow by absorbing mass in its neighborhood. By absorbing stars as well as by combining with other black holes, supermassive black holes can be formed with masses millions of times larger than those of the Sun.

Despite the invisibility of the interior, the presence of a black hole can be inferred through interaction with the rest of the matter. Astronomers have identified many possible black star holes in binary systems, studying their interaction with companion stars. At present there is a strong tendency toward consensus on accepting the idea that in the center of most galaxies there is a supermassive black hole. As a particular case, there is solid evidence that there is a black hole of over four million solar masses in the center of the Milky Way.

\section{Results}

The notion of body massively large enough to allow even light to escape was first mentioned in 1783 by geologist John Mitchell in his work to the Royal Society of England: "If the radius of a sphere of the same density as the Sun would exceed its radius in a ratio of 500 to 1 , a body that would fall from a very high height - infinite - would have the speed equal to the speed of light. Light is in turn attracted by the same force, proportional to the inertial mass of the sphere. Consequently, all the light emanating from such a body would immediately be attracted to its gravitational force. "-John Michell (Michell, 1784).

In 1796, Mathematician Pierre-Simon Laplace supports Mitchell's idea in the first two editions of the World System Exposition (Israel, 1989), but the idea was unlikely in the nineteenth century, when light was not known to be influenced by gravitational force (light was considered a massless wave and as such could not be influenced by gravity).

In 1915 Einstein published The Theory of Generalized Relativity, previously demonstrating that light is influenced by gravitational force. A few months later, Karl Schwarzschild finds a solution to Einstein's field equations describing the gravitational field of a spherical, symmetrical, non-rotatable body. A few months later, Johannes Droste, a student of Hendrik Lorentz, separately obtained the same solution for a point-like table detailing his properties (Droste, 1915). This solution has a strange behavior for a certain area (now called the Schwarzschild Raza) generating singularity, that is, some of the terms of Einstein's equations became infinite. The nature of this area was not fully understood at the time. In 1924, Arthur Eddington showed that the singularity disappeared after a change of coordinates, only in 1933 Georges Lemaître realized that in fact this means that the coordinate system is not a physical one (Fig. 1).

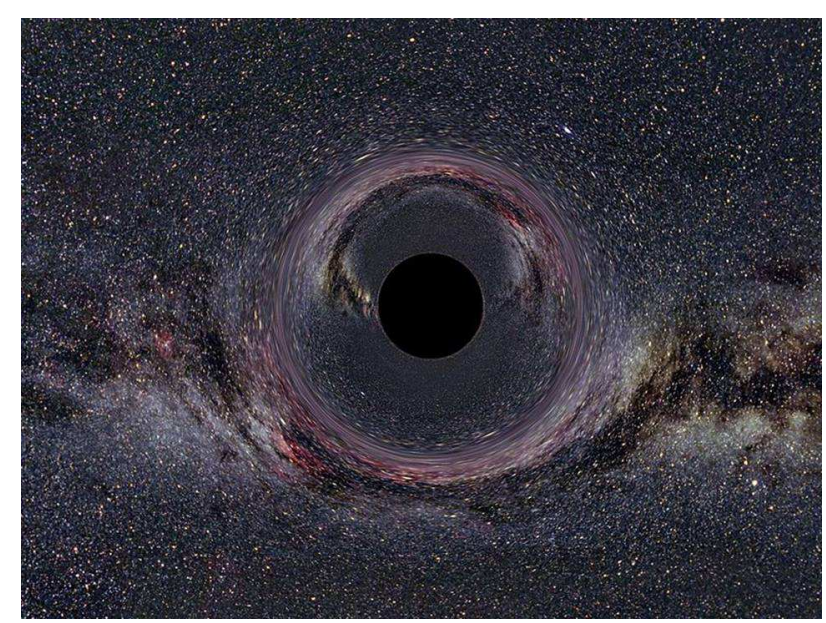

Fig. 1: A black hole

In 1931 Subrahmanyan Chandrasekhar argues according to the theory of relativity, a body that no longer emits radiation and has a mass greater than a certain limit (called the Chandrasekhar limit at 1.4 solar masses) must have infinite density. In other words, the object must have zero radius (Venkataraman, 1992). These arguments were opposed by many scholars of the day, such as Eddington and Lev Landau, who argued that an unknown mechanism would still halt the collapse. They were partially right: a slightly more dwarf white dwarf than the Chandrasekhar limit would give rise to a neutron star's gravitational collapse, which (according to Pauli's exclusionary principle) is stable.

In 1939, Robert Oppenheimer and H. Snyder emulate the idea that the neutron stars of about three solar masses (the Tolman-Oppenheimer-Volkoff limit) become the black holes collapse for the reasons indicated by Chandrasekhar and concluded that it is unlikely that any law of physics to prevent (at least for some stars) turning into black holes (Oppenheimer and Volkoff, 1939).

Oppenheimer and his collaborators interpret singularity at the edge of the Schwarzschild as the border of an area where time stops. This view is valid for an external observer, not for an observer who collapses to singularity. Due to this property, the stars were called frozen stars (the external observer would see the surface of the frozen star in time when the collapse takes the star below the Schwarzschild radius).

In 1958, David Finkelstein identifies the Schwarzschild surface, which he calls the event horizon, as a perfectly unidirectional membrane: causality can go one way (Finkelstein, 1958). These conclusions do not directly contradict Oppenheimer's results, but rather complement them by including the point of view of an observer who collapses to singularity. In 1967, Stephen Hawking and Roger Penrose demonstrate that the idea of black hole has left Einstein's theory of relativity and in some cases their formation is inevitable. The general 
interest increases with the discovery of pulsars (stars that emit a regular radio signal) which turned out to be neutron stars that rotate very fast. Neutron stars were then regarded (as black holes) as mere theoretical curiosities (Hewish, 1970). In 1976, Stephen Hawking demonstrates that once a black hole forms, it begins to lose mass radiating energy (Hawking radiation), which contradicts quantum physics. In 2004, a group of black holes (Fig. 2) was discovered that led to new theories about the distribution of black holes in the universe and the conclusion that there are five times more black holes than previously assumed (Castelvecchi, 2016).

Samir Mathur of Ohio State University, demonstrates that by modeling a black hole according to string theory, it appears to be a great "tangle of strings", Hawking radiation issued by it also having information about what is inside. String theory supports a model of the universe based on small vibrating strings instead of point-like particles (Gorder, 2015). In the Ursa Mare constellation a giant black hole (Q0906+6930) is discovered (in July 2004), the size of the black hole and its approximate age can provide information about the age of the universe. A supermassive black hole is a black hole with a massive mass, ranging from $10^{5}$ to $10^{10}$ times the Sun's mass.

Scientists believe that all galaxies, including our Milky Way galaxy, have supermassive black holes in their centers (Fig. 3-8).

It is supposed that our galaxy can have a supermassive black hole in the center in a constellation called Sagittarius A *, because recent estimates indicate that the central object contains 2.6 million solar masses but has a radius less than $17 \mathrm{~h}$ of light. Only a supermassive black hole can contain such a large table in such a small space.

There are several theories for the formation of black holes of this magnitude. The most likely thing is the slow accumulation of a black hole of normal size.

Another theory involves a giant cloud of gas that collapses and turns into a relativistic star of the size of several hundred thousand suns. Later, the star would become unstable due to the disturbances produced by the electron-positron pairs in its nucleus, which would then turn directly into a black hole without exploding so as to conserve the table.

At present, there seems to be a gap in the mass distribution observed in the black holes. The minimum mass of a supermassive black hole is the size of 33 solar masses.

Hawking solves the black holes paradox, demonstrating that the radiation emitted by a black hole contains information about its contents, but this information is very difficult to decipher by humans, having nothing in common with the information that entered the black hole.

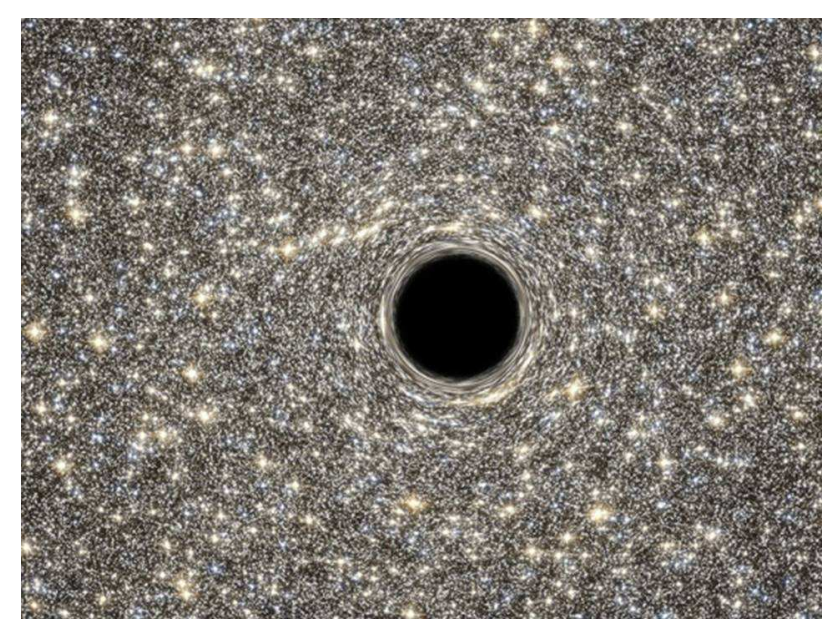

Fig. 2: A black hole, visualized here in the M60-UCD1 galaxy, was thought to lose information as it disappears

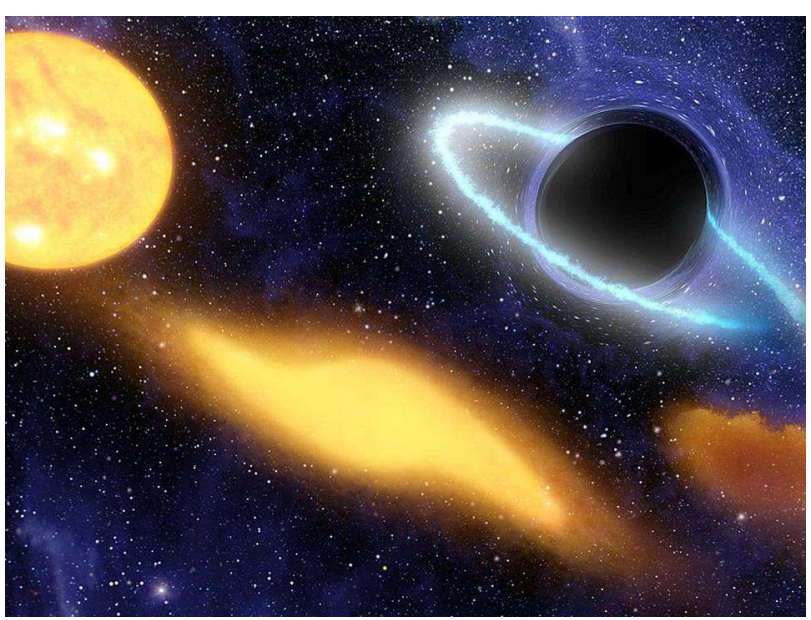

Fig. 3: Concept of a SMBH consuming matter from a nearby star

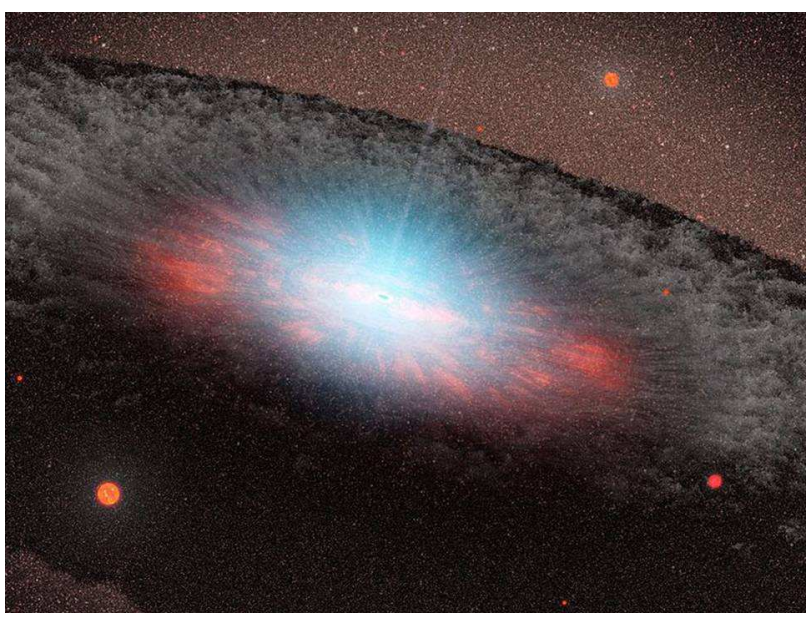

Fig. 4: Conception of a supermassive black hole and accretion disk 


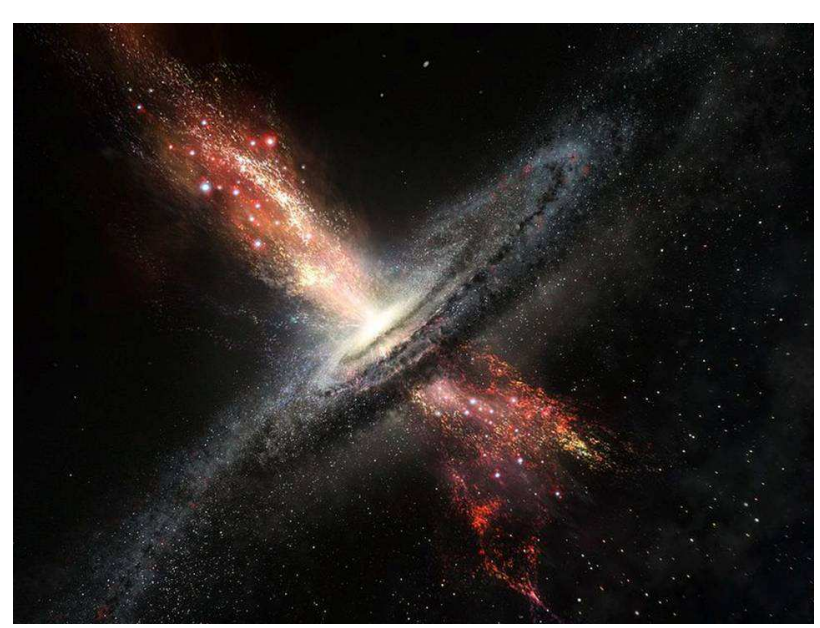

Fig. 5: Concept of stars born in winds from supermassive black holes

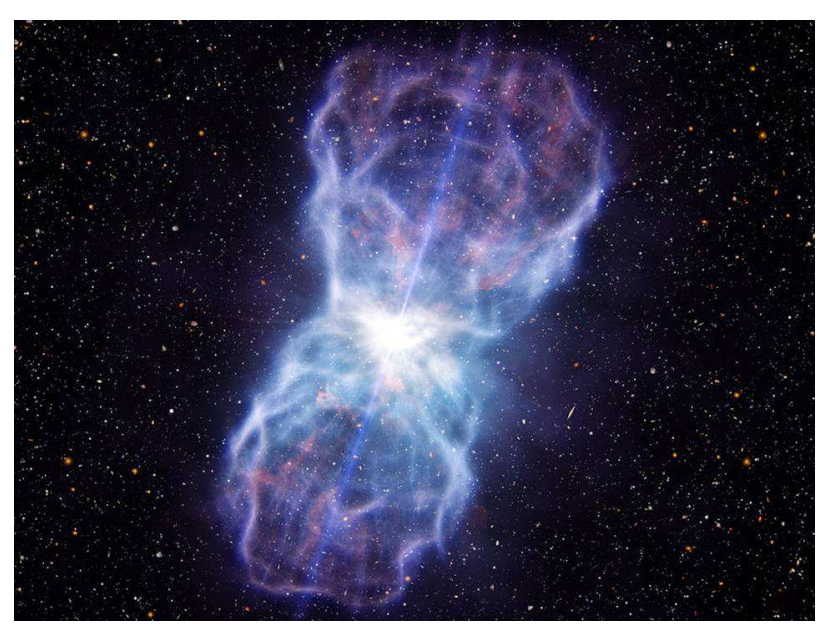

Fig. 6: Concept of the huge outflow ejected from the quasar SDSS J1106+1939

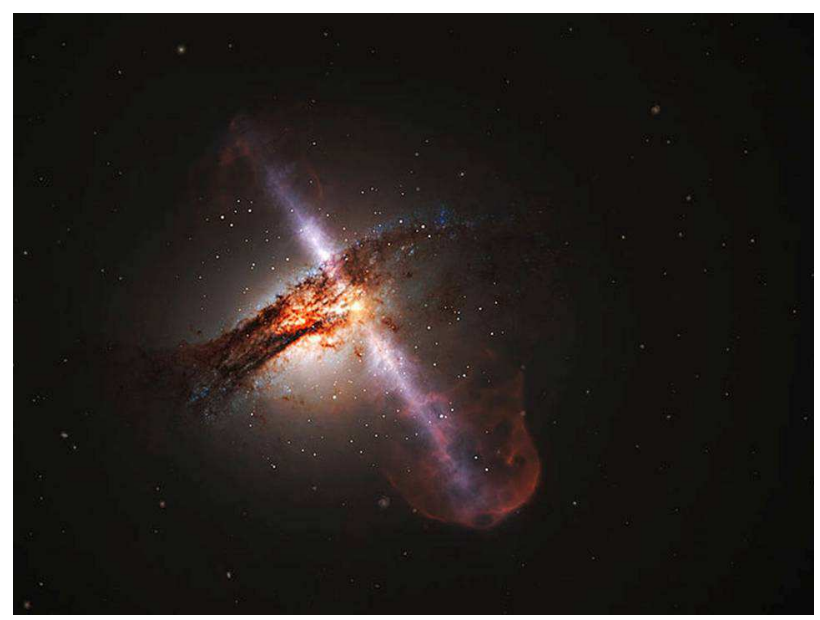

Fig. 7: Illustration of a galaxy with jets from a supermassive black hole

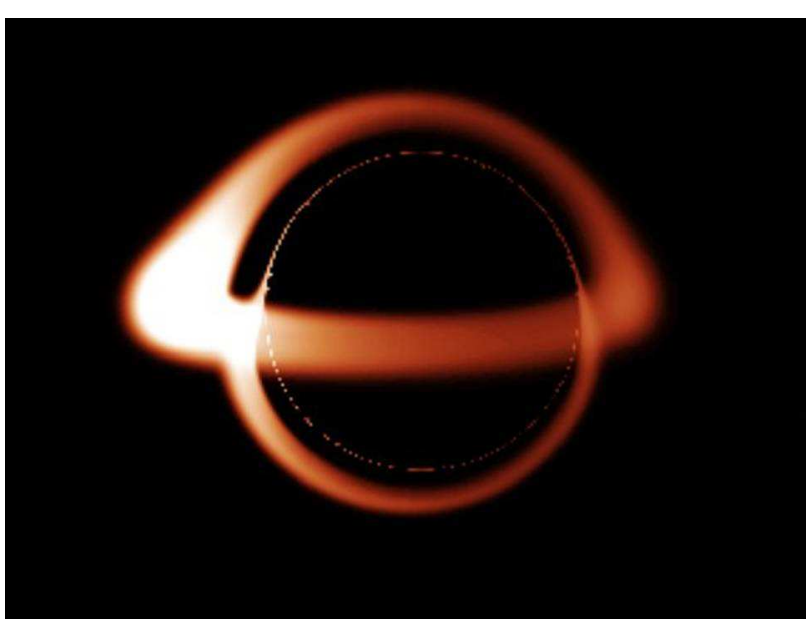

Fig. 8: Side view of a black hole with a transparent toroidal ring of ionized matter. This image shows the result of bending of light from behind the black hole, and it also shows the asymmetry arising by the Doppler effect from the extremely high orbital speed of the matter in the ring

In November 2004, a group of researchers discovered a black hole in our galaxy, orbiting at three light years by Sagittarius constellation. In February 2005, the SDSS J090745,0+24507, a giant star, leaves the Milky Way at twice the normal speed (about 0.0022 of the speed of light), proving the existence of a very large black hole in the center of the galaxy. There have been reports of observing microscopic black holes on the Earth in particle accelerators, but their existence could not be proven. The Hubble Telescope has recently identified two groups of black holes M15 and G1 but not in the Milky Way. April 2006 NASA simulates the merging of two black holes. Steve Allen, through NASA's Chandra studies, demonstrates that we can use black holes and fuel.

\section{Discussion}

The black hole uniqueness theorem states that once it becomes stable, after formation, a black hole is characterized by only three independent physical parameters: mass, electric charge and kinetic momentum. Any two black holes having the same values for these three parameters cannot be differentiated according to classical mechanics (non-quantum). These properties are special in that they are observable from the outside. For example, an electronically charged black hole rejects other tasks of the same meaning as any other object. Similarly, the total mass inside a sphere containing a black hole can be found using the Gaussian gravity correspondences at great distances of the black hole. Also the kinetic moment can be measured remotely. 
The simplest black hole has a table but does not have a kinetic moment. These black holes are often called Schwarzschild black holes, according to the German physicist Karl Schwarzschild, who discovered Einstein's field equations solution of 1915.

This was the first exact solution to the theory of general relativity in the field of Einstein's equations that was discovered, In accordance with Birkhoff's relativity theory, only the vacuum solution exhibits a spherical symmetry of space-time.

This means there is no observable difference between the gravitational field of such a black hole and any other similar spherical object. The popular notion of a black hole that "draws in it all" of what exists near it is therefore correct only near the horizon's black hole horizon; Further, the external gravitational field is identical to any other mass-like body.

In general, black hole solutions were discovered later in the 20th century. The Reissner-Nordström solution describes a black-charged electric hole, while Kerr measures the yields of a black hole through rotation (Reissner-Nordström, Geometry). More generally, known stationary Black Hole solution, Kerr-Newman metric, describes both the load and kinetic momentum.

When a star of about 20 times the Sun is exhausted, the "fuel" collapses, unable to sustain all the reactions that take place inside it. It explodes causing a mass explosion called the supernova. But the core of the star remains compact and the collapse continues.

The core particles are crushed from one another because of their own gravity until all that remains is a black hole.

A schematic explanation of a black hole would be the following: It is known that mass distorts space. What does that mean? If space was a stretched plan for Terra to exist in it, it distorted. In the place where the Earth is, the space is no longer plan but curved because there is a recess caused by the mass of the Earth. A black hole produces an extremely large recess in space.

A practical example would be the following: We have a lake. We imagine it to be the space. We lay some spheres in it that float and represent the celestial bodies. If a very powerful and especially deep water whirlpool appeared in the lake, all the water (which represents the space) and with it and the spheres (the celestial bodies) would be attracted to that whirlpool, the power with which the water (the space) is drawn in whirlpool is so great that spheres are impossible to escape.

NASA has Found the most Distant Black Hole (Fig. 9).

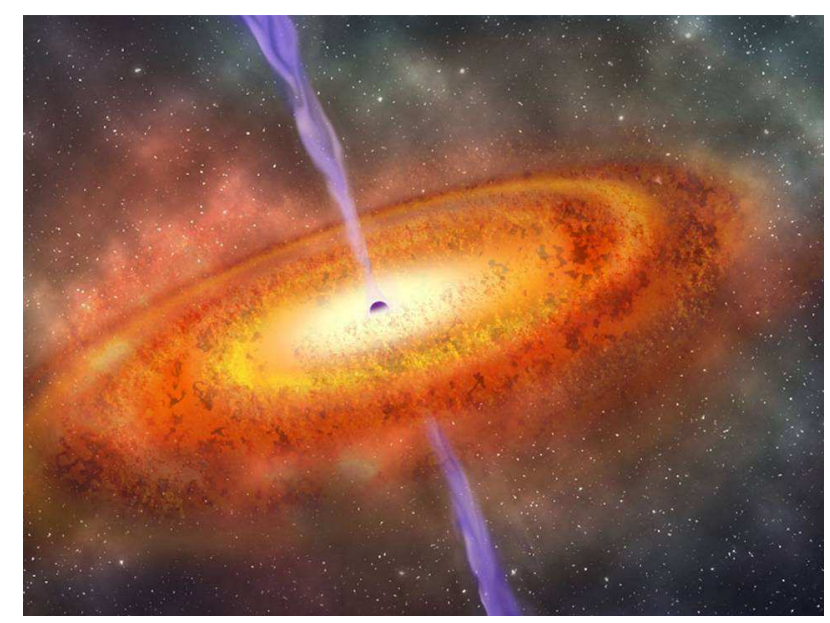

Fig. 9: NASA has found the most distant black hole

\section{Conclusion}

At the edge of a black hole there is an invisible "border" called the horizon of the event. Once this boundary is over nothing can escape from the black hole, not even light, which is why everything in a black hole remains invisible. Inside a black hole, despite appearances, it is supposed to be extremely bright because the light is also caught in the black hole. The matter absorbed by the black hole is subject to various physical effects as well as compression. At the center of a black hole is one of the most mysterious physical phenomena: Singularity. Singularity is a zero-point volume point, but contains a mass that tends to infinity. In the case of a black hole, singularity is the mass of a whole star at least 20 times greater than our Sun, concentrated at a point in space. Singularity has a colossal gravitational force and it gives the attraction of a black hole.

A black hole can embody a great deal of matter, despite its size not great because it compresses matter. The matter attracted by a black hole does not come into it with a straight trajectory, but turning in the shape of a spiral, getting closer and closer to the hole. While the black hole absorbs a lot of matter due to its rotation around the hole, the black hole just seems black because of the color of the material which, while rotating, can exceed the size of the black hole ten times. But the black hole remains at the center of the circle of matter, being visible.

A super-massive black hole is a real "space monster". It is millions of times larger than an ordinary black hole and can capture billions of times more matter than our Sun. These "monsters" can absorb the entire galaxy. Most large galaxies (eg the Milky Way) have a supermassive black hole at their center.

\section{Acknowledgement}

We acknowledge and thank Mr Taher M. AbuLebdeh, Associate Prof at North Carolina A and T State Univesity, United States and Mr Muftah H. El-Naas PhD 
MCIC FICCE QAFCO Chair Professor in Chemical Process Engineering Gas Processing Center College of Engineering Qatar University and Ms Shweta Agarwala, Senior Research Scientist at Singapore Center for 3D Printing Nanyang Technological University Singapore for their suggestions and comments.

\section{Funding Information}

Research contract: Contract number 36-5-4D/1986 from 24IV1985, beneficiary CNST RO (Romanian National Center for Science and Technology) Improving dynamic mechanisms internal combustion engines. All these matters are copyrighted. Copyrights: 548cgiywDssin, from: 22-04-2010, 08:48:48.

\section{Author's Contributions}

All the authors contributed equally to prepare, develop and carry out this manuscript.

\section{Ethics}

This article is original and contains unpublished material. The corresponding author confirms that all of the other authors have read and approved the manuscript and no ethical issues involved.

\section{References}

Aversa, R., F.I.T. Petrescu, R.V. Petrescu and A. Apicella, 2016a. Biomimetic FEA bone modeling for customized hybrid biological prostheses development. Am. J. Applied Sci., 13: 1060-1067. DOI: 10.3844/ajassp.2016.1060.1067

Aversa, R., D. Parcesepe, R.V. Petrescu, G. Chen and F.I.T. Petrescu et al., 2016b. Glassy amorphous metal injection molded induced morphological defects. Am. J. Applied Sci., 13: 1476-1482. DOI: 10.3844/ajassp.2016.1476.1482

Aversa, R., R.V. Petrescu, F.I.T. Petrescu and A. Apicella, 2016c. Smart-factory: Optimization and process control of composite centrifuged pipes. Am. J. Applied Sci., 13: 1330-1341.

DOI: 10.3844/ajassp.2016.1330.1341

Aversa, R., F. Tamburrino, R.V. Petrescu, F.I.T. Petrescu and M. Artur et al., 2016d. Biomechanically inspired shape memory effect machines driven by muscle like acting NiTi alloys. Am. J. Applied Sci., 13: 1264-1271.

DOI: 10.3844/ajassp.2016.1264.1271

Aversa, R., E.M. Buzea, R.V. Petrescu, A. Apicella and M. Neacsa et al., 2016e. Present a mechatronic system having able to determine the concentration of carotenoids. Am. J. Eng. Applied Sci., 9: 1106-1111. DOI: 10.3844/ajeassp.2016.1106.1111
Aversa, R., R.V. Petrescu, R. Sorrentino, F.I.T. Petrescu and A. Apicella, 2016f. Hybrid ceramo-polymeric nanocomposite for biomimetic scaffolds design and preparation. Am. J. Eng. Applied Sci., 9: 1096-1105. DOI: 10.3844/ajeassp.2016.1096.1105

Aversa, R., V. Perrotta, R.V. Petrescu, C. Misiano and F.I.T. Petrescu et al., 2016g. From structural colors to super-hydrophobicity and achromatic transparent protective coatings: Ion plating plasma assisted $\mathrm{TiO} 2$ and $\mathrm{SiO} 2$ Nano-film deposition. Am. J. Eng. Applied Sci., 9: 1037-1045.

DOI: 10.3844/ajeassp.2016.1037.1045

Aversa, R., R.V. Petrescu, F.I.T. Petrescu and A. Apicella, 2016h. Biomimetic and evolutionary design driven innovation in sustainable products development. Am. J. Eng. Applied Sci., 9: 1027-1036. DOI: 10.3844 /ajeassp.2016.1027.1036

Aversa, R., R.V. Petrescu, A. Apicella and F.I.T. Petrescu, 2016i. Mitochondria are naturally micro robots-a review. Am. J. Eng. Applied Sci., 9: 991-1002. DOI: 10.3844/ajeassp.2016.991.1002

Aversa, R., R.V. Petrescu, A. Apicella and F.I.T. Petrescu, 2016j. We are addicted to vitamins $C$ and E-A review. Am. J. Eng. Applied Sci., 9: 1003-1018. DOI: 10.3844/ajeassp.2016.1003.1018

Aversa, R., R.V. Petrescu, A. Apicella and F.I.T. Petrescu, 2016k. Physiologic human fluids and swelling behavior of hydrophilic biocompatible hybrid ceramo-polymeric materials. Am. J. Eng. Applied Sci., 9: 962-972.

DOI: 10.3844/ajeassp.2016.962.972

Aversa, R., R.V. Petrescu, A. Apicella and F.I.T. Petrescu, 20161. One can slow down the aging through antioxidants. Am. J. Eng. Applied Sci., 9: 1112-1126. DOI: 10.3844/ajeassp.2016.1112.1126

Aversa, R., R.V. Petrescu, A. Apicella and F.I.T. Petrescu, 2016m. About homeopathy or «Similia similibus curentur $\gg$. Am. J. Eng. Applied Sci., 9: 1164-1172. DOI: 10.3844/ajeassp.2016.1164.1172

Aversa, R., R.V. Petrescu, A. Apicella and F.I.T. Petrescu, 2016n. The basic elements of life's. Am. J. Eng. Applied Sci., 9: 1189-1197.

DOI: 10.3844 /ajeassp.2016.1189.1197

Aversa, R., F.I.T. Petrescu, R.V. Petrescu and A. Apicella, 2016o. Flexible stem trabecular prostheses. Am. J. Eng. Applied Sci., 9: 1213-1221. DOI: 10.3844/ajeassp.2016.1213.1221

Aversa, R., R.V.V. Petrescu, A. Apicella and F.I.T. Petrescu, 2017a. Nano-diamond hybrid materials for structural biomedical application. Am. J. Biochem. Biotechnol., 13: 34-41. DOI: 10.3844/ajbbsp.2017.34.41

Aversa, R., R.V. Petrescu, B. Akash, R.B. Bucinell and J.M. Corchado et al., 2017b. Kinematics and forces to a new model forging manipulator. Am. J. Applied Sci., 14: 60-80. DOI: 10.3844/ajassp.2017.60.80 
Aversa, R., R.V. Petrescu, A. Apicella, I.T.F. Petrescu and J.K. Calautit et al., 2017c. Something about the $\mathrm{V}$ engines design. Am. J. Applied Sci., 14: 34-52. DOI: 10.3844/ajassp.2017.34.52

Aversa, R., D. Parcesepe, R.V.V. Petrescu, F. Berto and G. Chen et al., 2017d. Process ability of bulk metallic glasses. Am. J. Applied Sci., 14: 294-301. DOI: 10.3844/ajassp.2017.294.301

Aversa, R., R.V.V. Petrescu, B. Akash, R.B. Bucinell and J.M. Corchado et al., 2017e. Something about the balancing of thermal motors. Am. J. Eng. Applied Sci., 10: 200.217. DOI: 10.3844/ajeassp.2017.200.217

Berto, F., R.V.V. Petrescu and F.I.T. Petrescu, 2016a. A review of recent results on $3 \mathrm{D}$ effects. Am. J. Eng. Applied Sci., 9:1247-1260.

Berto, F., R.V.V. Petrescu and F.I.T. Petrescu, $2016 \mathrm{~b}$. Three-dimensional in bonded joints: A short review. Am. J. Eng. Applied Sci., 9:1261-1268.

Berto, F., A. Gagani, R.V.V. Petrescu and F.I.T. Petrescu, 2016c. Key-hole notches in isostatic graphite: A review of some recent data. Am. J. Eng. Applied Sci., 9: 1292-1300.

Berto, F., A. Gagani, R. Aversa, R.V.V. Petrescu and A. Apicella et al., 2016d. Multiaxial fatigue strength to notched specimens made of 40CrMoV13.9. Am. J. Eng. Applied Sci., 9: 1269-1291.

Castelvecchi, D., 2016 Hawking's latest black-hole paper splits physicists, some welcome his latest report as a fresh way to solve a black-hole conundrum; others are unsure of its merits. Nature 27 January 2016 CAMBRIDGE, UK. https://www.nature.com/news/hawking-s-latestblack-hole-paper-splits-physicists-1.19236

Droste, J., 1915. On the field of a single centre in Einstein's theory of gravitation. Koninklijke Nederlandsche Akademie van Wetenschappen Proc., 17: 998-1011.

Finkelstein, D., 1958. Past-future asymmetry of the gravitational field of a point particle. Physical Rev., 110: 965-967.

Gorder, P.F., 2015. What's on the surface of a black hole? Not a "firewall" - and the nature of the universe depends on it, physicist explains. https://news.osu.edu/news/2015/06/16/fuzzyhologram/

Hewish, A., 1970. Pulsars. Ann. Rev. Astronomy Astrophysics, 8: 265-296.

Israel, W. 1989. Dark Stars: The Evolution of an Idea. In: Three Hundred Years of Gravitation, Hawking, S.W. and W. Israel, Cambridge University Press. ISBN-10: 0521379768.

Landau, E. and E. Bañados, 2017. Found: Most distant black hole, NASA, jet propulsion laboratory. Pasadena, California Institute Technol. https://www.jpl.nasa.gov/news/news.php? feature $=7$ 017
Michell, J., 1784. On the means of discovering the distance, magnitude and c. of the fixed stars, in consequence of the diminution of the velocity of their light, in case such a diminution should be found to take place in any of them and such other data should be procured from observations, as would be farther necessary for that purpose. Philosophical Transactions Royal Society, 74: 35-57.

Mirsayar, M.M., V.A. Joneidi, R.V.V. Petrescu, F.I.T. Petrescu and F. Berto, 2017. Extended MTSN criterion for fracture analysis of soda lime glass. Eng. Fracture Mechan., 178: 50-59.

DOI: 10.1016/j.engfracmech.2017.04.018

Oppenheimer, J.R. and G.M. Volkoff, 1939. On massive neutron cores. Physical Rev., 55: 374-381.

Petrescu, F.I.T. and J.K. Calautit, 2016a. About nano fusion and dynamic fusion. Am. J. Applied Sci., 13: 261-266.

Petrescu, F.I. and J.K. Calautit, 2016b. About the light dimensions. Am. J. Applied Sci., 13:321-325. DOI: 10.3844/ajassp.2016.321.325

Petrescu, F.I. and R.V. Petrescu, 2011 a. Memories about Flight. 1st Edn., CreateSpace, pp: 652.

Petrescu, F.I. and R.V. Petrescu, 2011b. Mechanical Systems, Serial and Parallel.1st Edn., lulu.com Publisher, London, UK. ISBN-10: 1446600394, pp: 124.

Petrescu, R.V. and F.I.T. Petrescu, 2012a. Northrop. 1st Edn., Books on Demand, ISBN-10: 3848209322 , pp: 142.

Petrescu, F.I. and R.V. Petrescu, 2012b. New Aircraft II. 1st Edn., Books on Demand, pp: 138.

Petrescu, F.I. and R.V. Petrescu, 2012c. MecatronicaSisteme Seriale Si Paralele. 1st Edn., Create Space Publisher, USA, ISBN-13: 978-1-4750-6613-5, pp: 128.

Petrescu, F.I. and R.V. Petrescu, 2012d. Kinematics of the planar quadrilateral mechanism. Engevista, 14: 345-348.

Petrescu, F.I. and R.V. Petrescu, 2016a. Parallel moving mechanical systems kinematics. ENGE-VISTA, 18: 455-491.

Petrescu, F.I. and R.V. Petrescu, 2016b. Direct and inverse kinematics to the anthropomorphic robots. ENGEVISTA, 18: 109-124.

Petrescu, F.I. and R.V. Petrescu, 2016c. Dynamic cinematic to a structure 2R. Revista Geintec-Gestao Inovacao E Tecnologias, 6: 3143-3154.

Petrescu, F.I. and R.V. Petrescu, 2013d. Cinematics of the 3R Dyad. Engevista, 15: 118-124.

Petrescu, F.I.T., 2009. New aircraft. Proceedings of the 3rd International Conference on Computational Mechanics, Oct. 29-30, Brasov, Romania.

Petrescu, F.I.T., 2012a. Cold Nuclear Fusion. 1st Edn., Create Space, USA, ISBN-10: 1478234261, pp: 80. 
Petrescu, F.I.T., 2012b. Particle Annihilation - a Source of Renewable Energy? Infinite Energy Magazine, LuLu Publishers, USA. http://blog.hasslberger.com/2012/02/particle_annihil ation - a sour.html

Petrescu, F.I.T.. ., 2016. Valorificarea Traditiei Ingineresti Romanesti-I: Create Space Publisher, USA. 1st Edn., CreateSpace Independent Publishing Platform, ISBN-10: 1536889946, pp: 152.

Petrescu, R.V.V., R. Aversa, A. Apicella, F. Berto and S. Li et al., 2016a. Ecosphere protection through green energy. Am. J. Applied Sci., 13: 1027-1032

Petrescu, F.I.T., A. Apicella, R.V.V. Petrescu, S.P. Kozaitis and R.B. Bucinell et al., $2016 \mathrm{~b}$. Environmental protection through nuclear energy. Am. J. Applied Sci., 13:941-946.

Petrescu, R.V., R. Aversa, A. Apicella and F.I. Petrescu, 2016c. Future medicine services robotics. Am. J. Eng. Applied Sci., 9: 1062-1087.

Petrescu, R.V. and F.I. Petrescu, 2013a. Lockheed Martin. 1st Edn., CreateSpace, pp: 114.

Petrescu, R.V. and F.I. Petrescu, 2013b. Northrop. 1st Edn., CreateSpace, pp: 96.

Petrescu, R.V. and F.I. Petrescu, 2013c. The Aviation History or New Aircraft I Color. 1st Edn., CreateSpace, pp: 292.

Petrescu, R.V., R. Aversa, B. Akash, F. Berto and A. Apicella et al., 2017a. Forces of a 3R robot. J. Mechatron. Robotics, 1: 1-14.

Petrescu, R.V., R. Aversa, B. Akash, F. Berto and A. Apicella et al., 2017b. Direct geometry and cinematic to the MP-3R systems. J. Mechatron. Robotics, 1: 15-23.

Petrescu, R.V., R. Aversa, B. Akash, F. Berto and A. Apicella et al., 2017c. Dynamic elements at MP3R. J. Mechatron. Robotics, 1: 24-37.

Petrescu, R.V., R. Aversa, B. Akash, F. Berto and A. Apicella et al., 2017d. Geometry and direct kinematics to MP3R with $4 \times 4$ operators. J. Mechatron. Robotics, 1: 38-46.

Petrescu, RV., R. Aversa, A. Apicella, M.M. Mirsayar and S. Kozaitis et al., 2017e. Current stage in the field of mechanisms with gears and rods. J. Mechatron. Robotics, 1: 47-57.

Petrescu, R.V., R. Aversa, A. Apicella, M.M. Mirsayar and S. Kozaitis et al., 2017f. Geometry and inverse kinematic at the MP3R mobile systems. J. Mechatron. Robotics, 1: 58-65.

Petrescu, R.V., R. Aversa, A. Apicella, M.M. Mirsayar and S. Kozaitis et al., 2017g. Synthesis of optimal trajectories with functions control at the level of the kinematic drive couplings. J. Mechatron. Robotics, 1: 66-74.

Petrescu, R.V., R. Aversa, A. Apicella, M.M. Mirsayar and S. Kozaitis et al., 2017h. The inverse kinematics of the plane system 2-3 in a mechatronic MP2R system by a trigonometric method. J. Mechatron. Robotics, 1: 75-87.
Petrescu, R.V., R. Aversa, A. Apicella, M.M. Mirsayar and S. Kozaitis et al., 2017i. Serial, anthropomorphic, spatial, mechatronic systems can be studied more simply in a plan. J. Mechatron. Robotics, 1: 88-97.

Petrescu, R.V., R. Aversa, A. Apicella, M.M. Mirsayar and S. Kozaitis et al., 2017j. Analysis and synthesis of mechanisms with bars and gears used in robots and manipulators. J. Mechatron. Robotics, 1: 98-108.

Petrescu, R.V., R. Aversa, A. Apicella, M.M. Mirsayar and S. Kozaitis et al., 2017k. Speeds and accelerations in direct kinematics to the MP3R systems. J. Mechatron. Robotics, 1: 109-117.

Petrescu, R.V., R. Aversa, A. Apicella, M.M. Mirsayar and S. Kozaitis et al., 20171. Geometry and determining the positions of a plan transporter manipulator. J. Mechatron. Robotics, 1: 118-126.

Reissner-Nordström, Charged black holes: The reissnernordström http://casa.colorado.edu/ ajsh/rn.html

Venkataraman, G., 1992. Chandrasekhar and his Limit. 1st Edn., Universities Press, ISBN-10: 817371035X, pp: 89.

\section{Source of Figures}

Fig. 1:

https://ro.wikipedia.org/wiki/Gaur\%C4\%83_neagr\%C4

\%83\#/media/File:Black_Hole_Milkyway.jpg

Fig. 2:

https://www.nature.com/news/hawking-s-latest-black-

hole-paper-splits-physicists- 1.19236

Fig. 3:

https://en.wikipedia.org/wiki/Supermassive_black_hole\# /media/File:Black_hole_consuming_star.jpg

Fig. 4:

https://en.wikipedia.org/wiki/Supermassive_black_hole\# /media/File:Supermassiveblackhole_nasajpl.jpg

Fig. 5:

https://en.wikipedia.org/wiki/Supermassive_black_hole\# $/$ media/File:Artist\%E2\%80\%99s_impression_of_stars_b orn_in_winds_from_supermassive_black_holes.jpg

Fig. 6:

https://en.wikipedia.org/wiki/Supermassive_black_hole\# /media/File:Artist $\%$ E2\%80\%99s_impression_of the hu ge_outflow_ejected_from_the_quasar_SDSS_J1106\%2B 1939.jpg

Fig. 7:

https://en.wikipedia.org/wiki/Supermassive_black_hole\# $/$ media/File:Artist\%E2\%80\%99s_illustration_of_galaxy_ with_jets_from_a_supermassive_black_hole.jpg

Fig. 8:

https://en.wikipedia.org/wiki/Supermassive_black_hole\# /media/File:IonringBlackhole.jpeg

Fig. 9:

https://www.jpl.nasa.gov/news/news.php?feature $=7017$ 